\title{
Theory of marx and engels change of hegel's way of thinking
}

\author{
Yanling Mei ${ }^{1, a}$ and Pengcheng $\mathrm{Li}^{2}$ \\ ${ }^{1}$ School of Law and Politics, Jiangsu Normal University, 210016 Xuzhou, China \\ ${ }^{2}$ Faculty of Humanities, Nanjing University of Aeronautics and Astronautics, 210016 Nanjing , China
}

\begin{abstract}
The thinking method and the research method is not only is the core content of philosophical methodology, is also the essence of philosophy. In this paper, from the thought method and the content of the research methods and the relationship between them, this paper expounds the Marx and Engels is in the clearing of Hegel to the top of the old philosophy, critical process, gradually formed from the concrete to the abstract to the concrete way of thinking. The establishment of the mode of thinking has a profound theoretical significance and great influence in reality. At present, we must adhere to and to use this way of thinking, to spend the crucial stage of reform.
\end{abstract}

\section{Introduction}

Every generation is in front of the inherited generation "of the existing environment based on" creation, human production and material production, spiritual production as well. Just as Plato is on the basis of the critical theory of Socrates and others created his own theory, Marx and Engels is to analyze, criticize Hegel and the main successor - youth Hegel and Feuerbach established his own theory on the basis of the building. So, to illustrate the Marxist philosophy of Hegel philosophy method and the research methods and how to change, you must first make clear is thought method and the content of the research methods and the relationship between them.

\section{Philosophy method and the research methods and philosophical methodology}

Through the study of the history of philosophy, we found that the philosophy is the most precious is the way. Philosophy is a theoretical and systematic world view and methodology, is people to reflect the existence of the world, meet people and their relationships of a form of social consciousness. It is different from empirical knowledge and specific science lies in its abstractness, universality of problem of an object, content of systemic and high generalization of abstract thinking expression; The task of philosophy is based on human practice and scientific research analysis to summarize the achievements of human knowledge, to sum up and summarize the people know the world from the different world outlook and methodology, and the world outlook and methodology for critical analysis and argument form system and can guide the scientific understanding of the world outlook and methodology of the world, provide people with understanding and transforming the sharp

a Corresponding author: YanlingMei@sina.com ideological weapon of the world. Therefore, fundamentally speaking, philosophy is how to know the world, how to transform the world human basic world view and methodology problems.

The essence of philosophy (theory of world outlook and theory) determines the research method and thinking method is the core content of methodology system. Philosophy from the Angle of the people of the whole world and human and human's practice to concerned, study to explore the problem of human liberation, it is through the study revealed, including the spirit between person and person, the rule and general nature of the world, from the contact person and the nature of the world for all, and the existence of the people, the people and the people of the practical problems and human liberation; And these problems put forward itself and analysis, the solving process is in a certain research method, thinking method and the organic unity and under the guidance and on the basis of complete.

Philosophy methodology refers to the philosopher needs, based on the theory of the actual and builds in answers to basic philosophical problems in the process of applying the idea of a series of methods and the research method, logic method, language expression method and other methods of system.

Philosophers, both as a group of "class", or "people" as a single individual, have experienced a from the unconscious, unconsciously use method to form a scientific and systematic methodology. As the main body of the philosophy of education and research the philosopher in the process of the basic philosophical problems, from their respective practical conditions, in a certain thought method and the research methods on the basis of, in answer to the FQP: the relationship of thinking and the existing problems and its derived problems, in the process of forming each are not identical to the whole, a general overview in parts of the world or 
the world views and opinions; At the same time in the process of this thought, its thought method and the research method has also been gradually development: or surpass the thinking mode of before, create a new methodology system; Or the reverse; Or there have been great. On the research methods of the philosopher and the thought method in the process of study, we found that they adhere to the concept of materialism or, or from the perspective of idealism to explain the world; Or isolated and one-sided, looking at things or apply dialectics comprehensive inspection and its development and changes; Or in the person of materialism view on the relationship between the nature and the view field insist that idealism position, or at first is a "from theory to theory of idealism, and gradually turned to embarks from the practice in the process of research through the theory again and accept the test of practice of the" new materialism "world outlook and methodology. So certain research methods is always a certain philosophical world outlook and the embodiment of the determined by its fundamental thought method and concrete application, and people are the most fundamental way of thinking and always reflect certain philosophical world view and reflect and carry out the people engaged in theoretical thinking, and theory of research method in [1].

For Marx thought method and the research methods and they form the logic of the theory of narrative method is just the opposite, thinking method and the research method is based on the practice from the object of practice and related to know (including from perceptual knowledge to rational knowledge of abstract thinking that is, from the concrete to the abstract), and the theory of narrative or logical expression comes from the abstract theory and realize the rational understanding of the specific (that is, from the most abstract and simple theory and thinking paradigm to have rich ideological content specific) based theoretical thinking and perceptual experience, namely Marx said "in form, narrative methods must be different from the research method", but in fact, they are two cognitive process of thinking are interconnected, the former is from perceptual practice to the perceptual knowledge and abstract thinking eventually rise to the abstract process of rational knowledge, the latter is the fruits of which has obtained the abstract theory and knowledge in the process of systematically theoretical logic understanding and expression. Philosopher in based on social practice, on the basis of in real life people oriented in the process of cognition and research, and the possession of material, must fully analyze its various development form, explore these forms of inner link, only the work is complete, realistic movement to the proper narrative. [2]"

Language expression of the spread of the theory of philosophy, the research and development also play a role that nots allow to ignore. "Near the line of words," also applies to philosophical works. From this perspective, Hegel's theory because of its actual arcane works from real life and less researchers, nature also limits the development of the theory, communication and research.

Other method is to point to each specific use of scientific methods and thought achievement in philosophy, it is not only the development and the limitation of human knowledge level and level of scientific development, study the needs and interests more by philosopher himself factors such as the role of the nature of the spread of the works and the research has a certain degree of influence.

\section{The thinking methods of marxist philosophy and the research methods}

Before all the old philosophy of marxism in ideological understanding methods have a common characteristic, that is in the process of research knowledge to and distort the understanding of the general and individual relations, put on the basis of practice, finally returned to the practice of the individual to general, from general to specific (i.e., concrete to abstract to concrete) cycles and the growing awareness of the relationship between artificial fracture, only capture a fragment in the process of cognition, and then out of it and know the basis of the practice of total process, distort it exaggerates the understanding of effective for understanding the general nature of the or general rule and method of ideological understanding, in accordance with the "from the more general to the individual", "from the abstract to the concrete research methods or way of thinking, from abstract thinking to abstract thinking of circular logic reasoning.

In succession, way of thinking on the basis of criticizing the old philosophy, Marx formed the practice materialism way of thinking and research methods. This method not only has realized the revolutionary change of Marxist philosophy of the old philosophy, and on the premise of epistemology and methodology, to the development of the Marxist philosophy itself and mature laid the ideological basis.

Of certain research methods is always with a certain method or ideological understanding route linking and adapt to, is to keep from practice to cognition, from perceptual knowledge to rational knowledge, that is, on the basis of the practice from content to feel and people's thought and the thought of practice materialism ideological understanding, or stick from the abstract concepts and ideas to the content and practice of the idealism of ideological understanding, directly decides the people in the theoretical research and the research methods of theoretical knowledge, adhere to the practical materialism method and concept of the course, will mean that proceed from the concrete practice, from the specific feeling and experience through the theory of abstract thinking to abstract a study method; But if insist on idealism ideological understanding route and method, it will mean proceed from abstract ideas and thoughts and along "from abstract to concrete" idea and research method to thinking about the problem, but it actually only from abstract thinking to abstract thinking. In real life, of course, in every process may exist in practice meet many times repeatedly, and the whole process is a cycle again, continuously developing and improving [3].

Marx established way of thinking and research methods from the concrete to the abstract, from individual to general. And the old materialism and idealism philosophy is different, in marxist philosophy, the concrete and individual not thinking abstract and specific 
individual, but the objective reality, practice and cognition directly in the face of the objective thing itself by the specific and individual. "Specific" here refers to the practice of specific objective realities (specific) specific to the perceptual knowledge, "abstract" refers to a specific from perceptual knowledge through the theory of abstract thinking to the abstract or general. From the material basis for the reality and the objective historical conditions, the following from concrete (reality) to abstract (theory or concept of the abstract), from individual to general materialism know route to get to know the world, this is just the first stage in the process of understanding marxist study or process, rather than the method of marxism and the research methods of all of them. Karl Marx's discourse research methods are mainly concentrated in the $<$ critique of political economy "preface" and "das kapital" the first volume of the 1872 second edition, in these two articles, namely political economics. In the previous article, Marx 'said: "if you really want to follow my readers, will be determined, from individual to general. [4]" and in these two articles repeatedly stressed that the study of political economy must be in accordance with the thought method of practice materialism: all the theory and abstract concept and consciousness can only rooted in the reality of social and historical conditions, only starting from the objective conditions of these realities, follow from concrete (objective reality) to abstract (theory of abstract), from individual to general understanding of the route, they can obtain the scientific explanation. Marx's theory of narrative methods or logic method from abstract to concrete, from the more general to the individual, this is just the reverse of thinking and research methods. Unlike the old philosophy, in the marxist philosophy, the "specific" here refers to the specific of abstract thinking, not only includes theoretical generalization of the practice of the objective reality concrete in the form of the abstract thinking. This is by human practice, marxist philosophy comes from practice and ultimately to guide people to go back to practice the fundamental characteristic of practice. We will the Marx from the concrete to the abstract thinking method and the research methods and from the abstract to the concrete combined narrative logic unified look, they just is based on the practice of people from perceptual knowledge is specific to the theory of abstract or general, then through concrete, abstract thinking of going back to the practice of the objective reality that a complete ideological understanding process. So "concrete to abstract - concrete..." Cycle continuously improve the development of the theoretical knowledge and the practice - know - practice again..." The understanding of the cycle development process and knowledge rules is completely consistent. In this sense we can say, before and after the two cognitive process of different method or complete unity and logic method, namely marxist philosophy in the broadest sense of the understanding method and the research method is the most complete expression. But marxist studies the process of second phase or in process, must be from the concrete to the abstract process of the first study, as the basis and premise, in order to ensure the objectivity and scientific materialism. For example, in "das kapital", Marx of labor and capital to produce goods such as category, from the angles such as economics, anthropology, historical materialism has carried on the concrete analysis, through from the concrete to the abstract objective comprehensive study, for they made a scientific definition, puts forward the scientific labor value theory and surplus value theory, the capitalist mode of production, and adapted and its production and exchange relations has carried on the complete and systematic study. The theoretical results not only guide the development of the nations of the world proletarian revolutionary movement, and through practical test proves that it is a scientific world outlook and methodology. But when in Marx's "das kapital" to formulate their based on historical materialism and dialectical materialism theory of economics and used to explain the contradiction of capitalism in real life, trend of historical development of capitalism and to guide the working class struggle, is adopted from the abstract theory to direct specific theory embody and reflect the reality of narrative logic.

\section{The marxist philosophy thinking of practical significance}

Horses, is the inheritance, to analyze, criticize Hegel's philosophy of abstract speculative idealism method in the process of building his own methodology system. This system not only has great theoretical significance, but also has far-reaching practical significance.

Marxist philosophy of Hegel philosophy method and the research methods change theoretical significance:

Old materialism and idealism in philosophical history philosophy have a common drawback: they will be the subject and object, understanding and practice, concrete and abstract separated one-sided "explaining the world", so it's hard to really know "things, realistic and sensibility", the birth of marxist philosophy over the state, it is on the premise of reality of individuals and the world, on the basis of practice, split after the two organically, make the laws of nature, society, history and thought understanding is closer to the truth; Horse, on the basis of practice materialism way understanding, established the materialist view of history, discovered the surplus value, comprehensive, systematically analyzes the history of human society form makes the theory weapon of the proletariat "spirit"; Old materialism to the objective world and people to reflect the objective world abstract is some kind of perceptual intuition, in this abstract perceptual intuitive world as the theoretical starting point; Idealism or directly to feel and experience as the theoretical starting point, or directly to a rational (some established theory premise), some objective spirit (Hegel this view) as the theoretical starting point, they are not understand both the perceptual and the rational, itself contains the understanding of the practice, is the person's each new discovery, the practical basis of the new theory, the understanding of the process itself is constant practice and understanding of the practice, repeated the process closely integrated, organic unity; And it is based on practice, people's understanding to the abstract thinking ability, after the abstract thinking of synthesis and analysis, realize the knowledge from perceptual to rational, from 
the concrete to the abstract, again by abstraction and rational to the emotional development of concrete, implement the perceptual and the rational, the theory and practice, subjective and objective, continuous combination of abstract and concrete, and since the guide practice. So only see old materialism of perceptual knowledge and perceptual intuitive world, idealism see only breaks away from practice of abstract thinking, reason and experience, they are between the practice and cognition, perceptual and rational, abstract and concrete, the general and individual, subjective and objective in the understanding of the link of practice, can't really understand the revolution, criticism of the perceptual practice activity (as a revolutionary, criticism of the perceptual practice activity is not only perceptual or is only part of the emotional, not feuerbach influenced by Hegel understood only belongs to the rational activities of thought and theory of practice),

Based on the correct way of thinking and scientific research methods of marxist human to the society, history, and various kinds of relations and the law of nature and of the world have a new understanding and mastering, "theory once learned the masses, also becomes a material force [7]", master the scientific theory of the proletariat from now on to the way a new revolution, opened up a new era in the history of mankind.

Marxist philosophy of Hegel philosophy method and the practical significance of the research methods change:

First: the influence on the proletarian movement: on the basis of historical materialism, Marx found the surplus value, reveal the secrets of capitalist exploitation of workers, improve the understanding level of the proletariat, enriched their revolutionary practice. From then on, mastered the advanced theory of proletariat boarded the stage of history, and gradually shows the power to change the world. This historic upheaval not only embodies in Germany vigorous on the workers' movement, but also in Europe and the rest of the world proletarian movement. Recognise their strength and the mission of the working class (before this is their revolutionary activities) coruscate gives unprecedented vitality, with the combination of capital and capitalist as closely unite and set off a vigorous proletarian revolution, opened a new chapter in human history.

Second: impact on world history: it is to use the methodology of marxism, starting from the actual conditions of Russia, Lenin analyzed the international situation at that time, led the Russian proletarian movement, broke the Marx put forward the "communism only as the dominant peoples' immediately 'simultaneous action just might be the experience, which is based on the common development of productivity and the common development of the world communication is associated with the premise of" the theory, established the first socialist country in the world, opened up a new era in the history of mankind.

Third: impact on our country: the theory of essence as well as the vanguard of the proletariat, the communist party in China by the master and development, with comrade MAO zedong as the core of the first generation of collective leadership, according to the reality of China, starting from the practice of Chinese revolution, on a constantly strengthen the party's organization construction and improve the level of theory of party members, the party should command the gun and forces seized power of rural areas to encircle the cities. After the practice proved that this theory is correct, it makes the oppressed and enslaved accounted for a quarter of the population in the world to overthrow the three mountains, have stood up from now on! This historic change not only changed the living conditions of the Chinese people, and promote the further development of the world proletarian movement, making procession of great contribution to the maintenance of world peace; The second generation of collective leadership with comrade deng xiaoping as the core, based on the analysis of the situation at home and abroad, according to China's national conditions, surrounding the ideological line of "emancipating the mind, seeking truth from facts" chose "taking economic construction as the center, stick to the four cardinal principles and press ahead with reform and opening-up" to develop, and also through the practice has proved that this theory is correct, it greatly mobilized the subjective initiative of the people, promoted the rapid development of productivity, makes the Chinese people not only can solve the problem of food and clothing, and moving towards a well-off life; Greatly improved China's international status and prestige, to increase the power of the world peace [8].

\section{Conclusions}

To sum up, the methodology of Marxism is very significant. We only in the study, master and flexible use, on the basis of marxist methodology, combined with China's actual, set out from practice to develop a realistic line, principles and policies; Have to return to practice and the theory is correct and accept the inspection from the practice... After such from practice to theory and practice, our party to lead the Chinese people of all ethnic groups, to achieve our goals.

\section{References}

1. B. Yan, Yuejiang Academic Journal 4, 5(2012).

2. Z.P. Yu, X.H. Meng, Journal of Xinjiang University 31, 4 (2003).

3. L. Wang , C. Li, J. Yi, Journal of Coastal Research $\mathbf{7 3}$ (2015).

4. X.M. He, Journal of Coastal Research 25, 3 (2005).

5. C. Ren, Wuhan University Journal (Humanity Sciences) 58, 6 (2005).

6. J. Wang, Journal of Southern Yangtze University:Humanities \& Social Sciences Edition 58 (2012).

7. X.G. Sun, Journal of Xi'an Jiaotong University(Social Sciences) 26, 4(2006).

8. H. Huang, Z.L. Liu, H.B. Liu, EBM 2010: International Conference On Engineering And Business Management 1-8 (2010). 